\title{
The Most Cited Articles in Anatomy: An Update Study
}

\author{
Emine Petekkaya* \\ Department of Anatomy, The Faculty of Medicine, Campus of Büyükçekmece, Turkey
}

*Corresponding author: Emine Petekkaya, Department of Anatomy, The Faculty of Medicine, University of Beykent, Campus of Büyükçekmece, 34520, Büyükçekmece -Istanbul, Turkey

\begin{tabular}{|c|c|}
\hline ARTICLE INFO & ABSTRACT \\
\hline $\begin{array}{l}\text { Received: 幽 October 11, } 2019 \\
\text { Published: 幽 October 21, } 2019\end{array}$ & $\begin{array}{l}\text { Purpose: In this bibliometric study, it has been aimed to conduct multi-dimensional } \\
\text { citation analysis of the top } 100 \text { cited articles in anatomy field and to create an easy access } \\
\text { for researchers in this dynamic field. }\end{array}$ \\
\hline $\begin{array}{l}\text { Citation: Emine Petekkaya. The Most Cit- } \\
\text { ed Articles in Anatomy: An Update Study. } \\
\text { Biomed J Sci \& Tech Res 22(2)-2019. } \\
\text { BJSTR. MS.ID.003717. }\end{array}$ & $\begin{array}{l}\text { Methods: The word "anatomy, which is used as a search term was written and } \\
\text { queried into Thomson Reuter's } 2019 \text { Web of Science database to list all relevant articles } \\
\text { in this field. The top } 100 \text { cited articles were analyzed by topic, journal, author, year, } \\
\text { institution, level of evidence, adjusted citation index and also impact factor. }\end{array}$ \\
\hline $\begin{array}{l}\text { Keywords: Anatomy; Top-Cited; Biblio- } \\
\text { metric Analysis; Trend Topic }\end{array}$ & $\begin{array}{l}\text { Results: } 135.275 \text { eligible articles were found, and we had chosen the top } 100 \text { cited, } \\
\text { in the anatomy field, of these articles by a bibliometric criterion. The mean citation }\end{array}$ \\
\hline $\begin{array}{l}\text { Abbreviations: ACI: Adjusted Citation } \\
\text { Index; IF: Impact Factor; WoS: Web of } \\
\text { Science; SD: Standard Deviation }\end{array}$ & $\begin{array}{l}\text { number for the highly cited articles was } 4.471 \text { (range:295-4471). The most cited article } \\
\text { on anatomy was "The brain's default network: Anatomy, function, and relevance to } \\
\text { disease" ( } 4471 \text { citations) conducted by Buckner RL et al. "Ann N Y Acad Sci" journal } \\
\text { made the biggest contribution to the top } 100 \text { list with } 10 \text { articles whereas the most cited } \\
\text { article originated from the Neuroimage. The country and year with most publications } \\
\text { were the USA and } 2003 \text { respectively. University of London ( } \mathrm{n}=13 \text { ) and University College } \\
\text { London ( }=10 \text { ) were the most prolific institutions. Conclusion: Although anatomic-based } \\
\text { studies are increasingly evolving towards neuroanatomy and neuroscience, anatomical } \\
\text { morphology studies still important. However, it has been understood that more research } \\
\text { is needed to determine the forces that affect the direction of neuroanatomical research } \\
\text { in new technology-based neuroscience and neuroimaging studies. }\end{array}$ \\
\hline
\end{tabular}

\section{Introduction}

Science has reached its modern level with the developments it has shown in the history process. Each scientific progress is based on observations and ideas developed by previous researchers. Anatomy has maintained its importance throughout history as the most fundamental and essential component of medical science. Centuries ago, Hippocrates emphasized this importance with his that quote: "The nature of the body is the beginning of the medical science" [1]. Although the first written evidence of the history of ancient medicine was found in the process from Egyptian Papyrus (3000-2500 BCE) up to Andreas Vesalius of Brussels (1514-1564), founder of the modern human Anatomy; a lot more written sources on Anatomy have been provided in the process from Vesalius up to the present and thus massive information was obtained $[2,3]$. The press of sheets introduced by Vesalius in 1538 on loose leaves was considered as a direct descendant of the ancient manuscript [4]. The manuscripts of Leonardo da Vinci (1452-1519), as one of the earliest contributors to the history of anatomy and, accordingly, medical studies, were published in the form of facsimile edition between 1898-1916 and later for conservation purposes, in the early 1970s, all of his drawings were edited together with relevant notes and published in 1979 [5]. Information obtained through dissections of cadaver has been the most important and fundamental source for the publication of written sources. In addition to dissection studies that still continue to be relevant, clarification of researches by developing of radiological methods over time and increase of rat and laboratory experiments provided more information in the field of anatomy and thus directing the clinic. 
Bibliometric study is the quantitative analysis of the publications in the literature via statistical methods [6]. Bibliometric studies are carried out in order to determine which topics the current research focuses on. This adventure, which began with the first bibliometric analysis study published in 1987 by Garfield E. in JAMA [7], continued with bibliometric studies in different fields of medicine in the following years. In the current literature, the presence of bibliometric studies conducted mainly in clinical areas in recent years has attracted attention. Bibliometric studies on neuroanatomic structures of the insula were able to be found with a study conducted in the field of radiological anatomy that draws attention to the current trend with a specific perspective in the field of anatomy, one of the basic medical fields. After recognizing the deficiency in this field, in terms of showing trend topics in the field of Anatomy or determining trends in the field, the top 100 cited articles in anatomy were analyzed systematically and with a versatile perspective through data obtained from Web of Science (WoS) and PubMed. In this study, the number of citations in the ranking; number of citations; adjusted citation index (ACI); citations of publications by years; journals and institutes in which publications were published; country origins of publications; the most common subject of top cited articles; authors of articles; correlation between citation and adjusted citation index (ACI); impact factor (IF); general trends in the field of Anatomy were determined.

\section{Methods}

\section{Data Collection and Inclusion Criteria}

The data used in bibliometric citation analysis in this study were obtained from Thomson Reuters' WoS Core Collection database (Philadelphia, Pennsylvania, USA) and PubMed (US National Library of Medicine-National Institutes of Health). The WoS database was accessed for the period between 1975 and 2019 by using "Anatomy" keyword (data accessed May 23, 2019). As a result, 135,275 articles were acquired in total and the top 100 cited articles were analyzed. Articles that are accessed when the term of "Anatomy" is written and cover the anatomy word which is also used to examine the main structure of an institution, event or phenomenon in the meaning of the word only, were excluded from the study. In determining out-of-the field studies, some terms which take place in the form of functional neuroanatomy studies but are found to be specifically used in physiology-weighted studies when the terms they contain are examined, were included in exclusion criteria. After examining the terms of Pubmed MESH and perusing the abstracts of the articles, these terms were determined as "default, network, semantic processing, spatial processing, perception, memory, working memory, and circuitry". In this context, original research articles, editorial articles, expert opinion and responsible studies, review articles and case studies were included in the study.

In addition, PubMed was used to obtain additional data about the study. For the purpose of abbreviation, most of the tables showing the obtained data were limited to quantitative values as " 2 or more and 3 or more". In addition, due to long period in which the articles published in earlier years may be cited, in order to minimize time-based bias that may arise, "Adjusted Citation Index" (ACI), which was also used in the previous bibliometric analyzes [8], is shown in Appendix 1. Number of citations/ (2019-year of publication) formula was used to calculate ACI. The evidence levels of the topic trend articles were made by using the SIGN 50 (Scottish Intercollegiate Guideline Network). Accordingly, the level of evidence of the top 100 cited articles was detected in accordance with SIGN criteria. Accordingly, Group A evidence (levels 1a and 1b) comprised randomized clinical trials (RCT) or meta-analysis of RCT. Group B evidence (levels 2a, 2b, and 3) comprised cohort studies, case-control studies, and comparison of two or more groups where data were collected retrospectively, as well as semi-experimental studies. Group C evidence (level 4) comprised case series and expert opinions or expert committee reports (excluding levels 1 and 3 evidence). Group D evidence (level 5) comprised case reports.

\section{Statistical Analysis}

In this study, mainly descriptive statistical methods were used. All the data obtained are defined as percentage, number, bar chart or mean \pm Standard Deviation (SD) in the tables.

\section{Ethics Statement}

As the correspondant author, it is committed that this research is conducted in accordance with the corporate principles. As the principal author, it is committed that this research is conducted in accordance with the principles of World Medical Association Declaration of Helsinki "Ethical Principles for Medical Research involving Human Subjects". In this study, since bibliometric analysis and citation analysis of current published classical studies are performed, no ethics committee approval was received.

\section{Results}

The Top100 Time cited mean of 135.275 article published in the field of Anatomy between the years of 1975 and 2019 was found to be $634.83 \pm 669.99$ (range: $295-4471 / n=100$ ), the mean ACI was $35.38 \pm 44.97$ (range: $8.9-372.58 / n=100$ ). All articles were published in English. Top100 articles in the field of Anatomy and ACI were listed in Appendix 1 and sorted in decreasing order according to the number of citations (Appendix 1). It was determined that the name of the top cited article in the field of Anatomy was “The brain's default network: Anatomy, function, and relevance to disease" 2008; 1124:1-38, which was published by Buckner RL et al. in the field of neuroscience in the journal of "Ann N Y Acad Sci". In addition, it was found that 9 articles were cited more than 1.000 times and at the same time, this article was again the first article in the T100 with the highest mean of ACI (372.58). Also, according to Appendix 1, 6 articles were among the first 10 articles in terms of both times cited most and ACI rankings. It was seen that Price CJ and Zilles $\mathrm{K}$ were sharing the first rankings 
in T100 articles with their four articles each (Table 1). When the number of classic articles published by years is examined, it was found that it showed a Poisson distribution between the years of 1993-2013. The highest point of this distribution was found to correspond to 2003 (Figure 1). It was seen that in the distribution by years, on the other hand, there was an increase in the number of publications especially between the years of 1997-2010 (Figure
2). It was thought that it was the period when trend in anatomy (neuroscience-neuroanatomy) was in the term of transition and peak. It was observed that 51 of the T100 studies were published in 2000 and later. It was determined that the oldest trial among the Top100 articles was carried out by Van den Pol AN and published in J Comp Neurol. In 1980, the newest trial, on the other hand, was published in J Anat. In 2013 by [8].

Table 1: The most common authors with two and more in the top 100 cited articles.

\begin{tabular}{|c|c|c|}
\hline Author & Affliation & Number \\
\hline Price CJ & Institute of Neurology, Queen Square, London, (UK) & 4 \\
\hline Zilles K & Institute of Neuroscience and Medicine INM-1, Research Centre Jülich, Jülich, Germany & 4 \\
\hline Catani M & $\begin{array}{c}\text { NatBrainLab, Department of Neuroimaging, Institute of Psychiatry, Psychology and Neuroscience, King's College } \\
\text { London, De Crespigny Park, London, UK }\end{array}$ & 3 \\
\hline Frackowiak RSJ & Institute of Neurology, University College London, London, WC1N 3BG, UK & 3 \\
\hline Schleicher A & Institute of Neuroscience and Medicine, INM-1, Research Centre Jülich, Jülich, Germany & 3 \\
\hline Bürgel U & Department of Neurosurgery, University Hospital, RWTH Aachen, Aachen, Germany. & 3 \\
\hline Evans AC & Department of Bioengineering, Rice University, 6100 Main St., Houston, TX 77005, United States of America & 2 \\
\hline Ffytche DH & Institute of Psychiatry, King's College London, De Crespigny Park, London, SE5 8AF, United Kingdom. & 2 \\
\hline Fink GR & $\begin{array}{c}\text { Department of Neurology, Faculty of Medicine and University Hospital Cologne, University of Cologne, Cologne, } \\
\text { Germany. }\end{array}$ & 2 \\
\hline Fischl B & $\begin{array}{l}\text { Athinoula A. Martinos Center for Biomedical Imaging, Department of Radiology, Massachusetts General Hospital, } \\
\text { Charlestown, MA, 02129, United States; Department of Radiology, Harvard Medical School, United States; Division of } \\
\text { Health Sciences and Technology and Engineering and Computer Science MIT, Cambridge, MA, United States. }\end{array}$ & 2 \\
\hline Freund HJ & Fritz-Haber-Institut der Max-Planck-Gesellschaft, Faradayweg 4-6, 14195 Berlin, Germany. & 2 \\
\hline Friston $\mathrm{KJ}$ & $\begin{array}{c}\text { Wellcome Trust Centre for Neuroimaging, Institute of Neurology, University College London, London, United } \\
\text { Kingdom. }\end{array}$ & 2 \\
\hline $\mathrm{Fu} \mathrm{FH}$ & $\begin{array}{l}\text { Department of Orthopaedic Surgery, Center for Sports Medicine, University of Pittsburgh, Pittsburgh, Pennsylvania, } \\
\text { USA }\end{array}$ & 2 \\
\hline Giedd JN & $\begin{array}{l}\text { The Division of Child and Adolescent Psychiatry, Department of Psychiatry, University of California, San Diego, La } \\
\text { Jolla. }\end{array}$ & 2 \\
\hline Hazrati LN & Department of Pediatric Laboratory Medicine, The Hospital for Sick Children, Toronto, Canada & 2 \\
\hline Jones DK & USGS, 2329 West Orton Circle, West Valley City, UT, 84119, USA & 2 \\
\hline Joshi S & Division of Cardiology, University of Connecticut, Farmington, CT, USA. & 2 \\
\hline Miller MI & $\begin{array}{c}\text { Center for Imaging Science, Johns Hopkins University, Baltimore, MD, United States; Department of Biomedical } \\
\text { Engineering, Johns Hopkins University, Baltimore, MD, United States; Institute for Computational Medicine, Johns } \\
\text { Hopkins University, Baltimore, MD, United States. }\end{array}$ & 2 \\
\hline Parent A & $\begin{array}{l}\text { Department of Biological Sciences, Université du Québec à Montréal (UQÀM), C.P. 8888, succursale Centre-Ville, } \\
\text { Montreal (Quebec), H3C 3P8, Canada; CHU Sainte-Justine (CRME) } 5200 \text { rue Bélanger Est, Montreal (Quebec), H1T } \\
\text { 1C9, Canada. }\end{array}$ & 2 \\
\hline Paus T & Departments of Psychology and Psychiatry, University of Toronto, Canada (T.P.) & 2 \\
\hline Petrides M & Department of Neurology and Neurosurgery, Montreal Neurological Institute, McGill University, Montreal, QC, Canada & 2 \\
\hline Rademacher J & Department of Biomolecular Systems, Max Planck Institute of Colloids and Interfaces, 14424 Potsdam, Germany. & 2 \\
\hline Rammani N & Department of Psychology, Royal Holloway, University of London TWO 0EX, UK. & 2 \\
\hline Schormann T & Institute for Anatomy, Heinrich-Heine-University Düsseldorf, Universitätsstr. 1, Düsseldorf & 2 \\
\hline Wise RJS & Division of Brain Sciences, Imperial College London, Hammersmith Hospital, London, UK. & 2 \\
\hline
\end{tabular}




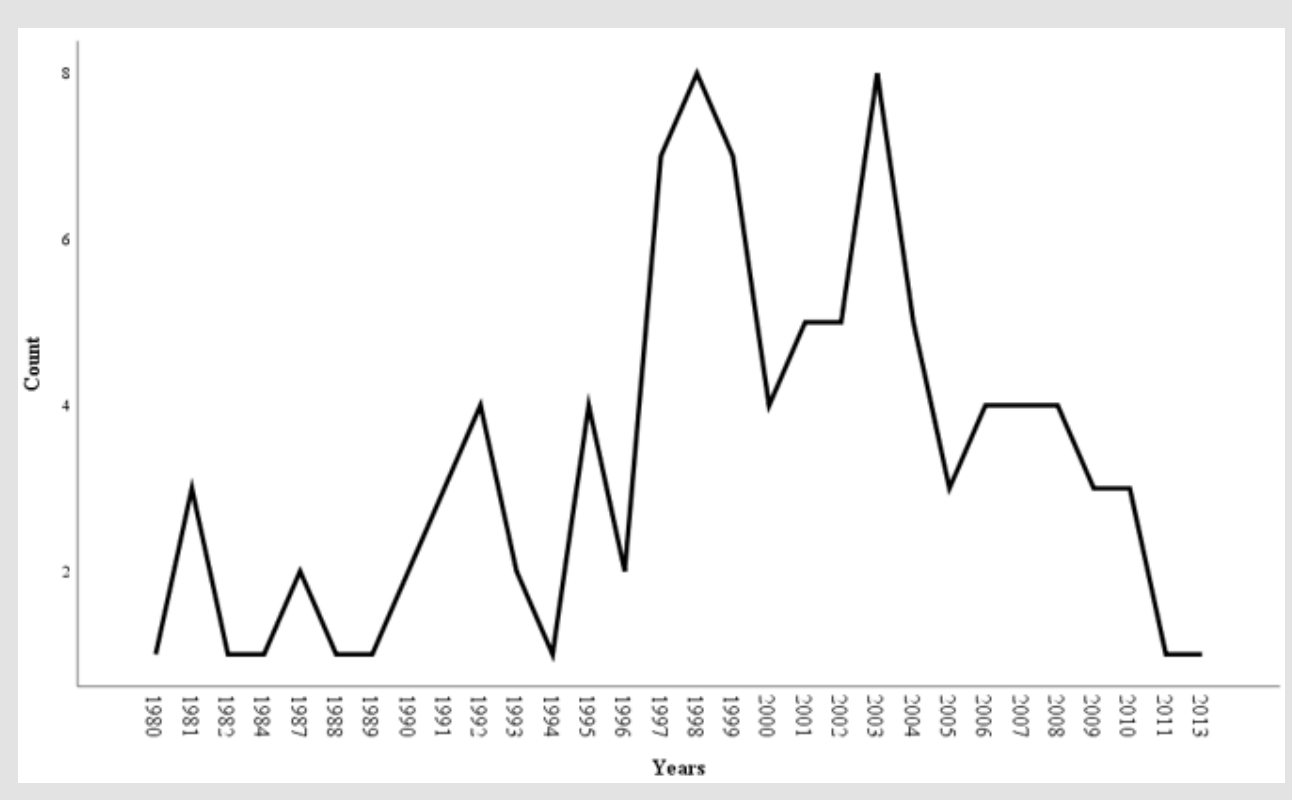

Figure 1: Citations in each year.

Sum of Times Cited per Year

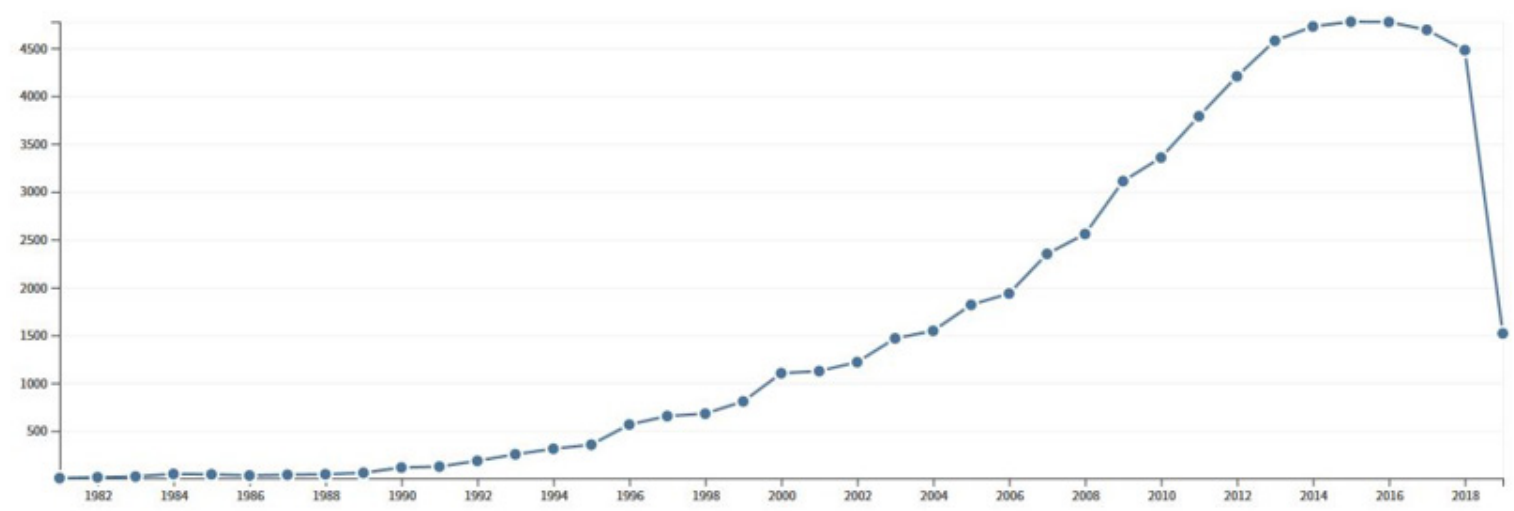

Figure 2: Citations per year.

It was observed that, in the evaluation of the study subjects among the Top 100 articles, basic field studies cover the first rank in the majority with a weight of $80 \%$. It was determined that interdisciplinary studies were at the second rank with the percentage of $11 \%$ and clinical research was at the third rank with $9 \%$. The fact that interdisciplinary studies took part in a higher ranking in comparison with clinical research was approached by the inclusion of a new field of study as a methodological method and dissemination processes of methods increase the interdisciplinary approaches. Neuroimaging trials based on radiological anatomy were thought to be the cause of this process, in particular. It was determined that among the basic field studies, 37 of the top cited articles were experimental studies and 34 of them were review studies. The distribution of 11 interdisciplinary articles were found as experimental study (4) and clinical study (3). It was observed that the majority of the 9 clinical field studies were accumulated in randomized controlled experimental trial (RCT) (5) (Table 2). According to the geographic origin of the top 100 list given in Table 3 , it was seen that contribution was made to Top 100 articles from 14 countries. The countries with the highest publication source number were USA ( $n=50)$, England ( $n=20)$, Canada ( $n=13)$, Germany $(n=13)$ and France $(n=8)$ respectively. The institutes contributed to the publication most were found as University of London $(n=15)$ and University College London $(n=10)$, Harvard University $(n=7)$ and McGill University $(n=7)$. Although most of the publications among the other T100 were published by the universities in USA, it was seen that England was at the forefront in T100 in the field of anatomy (Table 4). 
Table 2: Study design and levels of evidence by SIGN* of the top 100 cited articles.

\begin{tabular}{|c|c|c|c|}
\hline Study type and sub-type & Level of evidence & Group & Number \\
\hline \multicolumn{4}{|l|}{ Basic science } \\
\hline Review & 4 & $\mathrm{C}$ & 34 \\
\hline Experimental study & 2 & A & 37 \\
\hline $\begin{array}{l}\text { Experimental and } \\
\text { observational study }\end{array}$ & 3 & B & 2 \\
\hline Meta-analysis of RCT & 1 & A & 1 \\
\hline $\begin{array}{l}\text { Randomized controlled trial } \\
\text { (RCT) }\end{array}$ & 1 & $\mathrm{~B}$ & 3 \\
\hline Expert opinion & 4 & $\mathrm{C}$ & 1 \\
\hline Survey research & 3 & B & 1 \\
\hline Letter to editör & 4 & $\mathrm{C}$ & 1 \\
\hline \multicolumn{4}{|l|}{ Interdisciplinary study } \\
\hline Experimental study & 2 & A & 4 \\
\hline Clinical study & 2 & A & 3 \\
\hline $\begin{array}{l}\text { Randomized controlled trial } \\
\text { (RCT) }\end{array}$ & 1 & B & 1 \\
\hline $\begin{array}{l}\text { Experimental and } \\
\text { observational study }\end{array}$ & 3 & B & 1 \\
\hline Review & 4 & $\mathrm{C}$ & 1 \\
\hline Case-control study & 3 & B & 1 \\
\hline \multicolumn{4}{|l|}{ Clinical research } \\
\hline $\begin{array}{l}\text { Randomized controlled trial } \\
\text { (RCT) }\end{array}$ & 1 & $\mathrm{~A}$ & 5 \\
\hline Quasi-experimental study & 2 & B & 1 \\
\hline Case-control study & 3 & B & 1 \\
\hline Experimental study & 2 & A & 1 \\
\hline Clinical study & 2 & $\mathrm{~A}$ & 1 \\
\hline
\end{tabular}

*SIGN: Scottish Intercollegiate Guidelines Network; SIGN 50 (in: A Guideline developer's handbook Re, November 2011).

Table 3: The most common listed countries in the top 100 cited articles.

\begin{tabular}{|c|c|}
\hline Country & Number \\
\hline USA & $\mathbf{5 0}$ \\
\hline England & 20 \\
\hline Canada & 13 \\
\hline Germany & 13 \\
\hline France & 8 \\
\hline Italy & 7 \\
\hline Switzerland & 5 \\
\hline Australia & 3 \\
\hline Netherlands & 3 \\
\hline Sweden & 3 \\
\hline Japan & 2 \\
\hline
\end{tabular}

\begin{tabular}{|c|c|}
\hline Wales & 2 \\
\hline Belgium & 1 \\
\hline South Africa & 1 \\
\hline
\end{tabular}

Table 4: Institutions of origin with three or more in the top 100 cited articles.

\begin{tabular}{|c|c|}
\hline Institution & Number \\
\hline Universtiy of London (England) & 15 \\
\hline University College London (England) & 10 \\
\hline Harvard University (USA) & 7 \\
\hline Mcgill University (Canada) & 7 \\
\hline Heinrich Heine University Dusseldorf (Germany) & 5 \\
\hline Helmholtz Association (Germany) & 5 \\
\hline Imperial College London (England) & 5 \\
\hline $\begin{array}{l}\text { Institut National De La Sante Et De La Recherche Medicale } \\
\text { Inserm (France) }\end{array}$ & 5 \\
\hline National Institutes of Health NIH USA (USA) & 5 \\
\hline Research Center Julich (Germany) & 5 \\
\hline University of California System (USA) & 5 \\
\hline Kings College London (England) & 4 \\
\hline Massachusetts Genaral Hospital (USA) & 4 \\
\hline University of Oxford (England) & 4 \\
\hline VA Boston Healthcare System (USA) & 4 \\
\hline Assistance Publique Hopitaux Paris APHP (France) & 3 \\
\hline Duke University (USA) & 3 \\
\hline Hopital Universitaire Pitie Salpetriere APHP (France) & 3 \\
\hline Laval University (Canada) & 3 \\
\hline MRC Laboratory Molecular Biology (England) & 3 \\
\hline NIH National Institute of Mental Health NIMH (USA) & 3 \\
\hline $\begin{array}{l}\text { Pennsylvania Commonwealth System of Higher Education } \\
\text { PCSHE (USA) }\end{array}$ & 3 \\
\hline Sorbonne Universite (France) & 3 \\
\hline University of Pittsburgh (USA) & 3 \\
\hline Brown University (USA) & 2 \\
\hline
\end{tabular}

In the present study 91 of T100 were published in 25 journals that had an impact factor (IF) of $\geq 4.24$ (Table-3). According to Clarivate Analytics (2017) IF means of 17 journals was found as $4.92 \pm 4.78$ (range: $0-21.21 / \mathrm{n}=25$ ) and $\mathrm{H}$ index mean $264.8 \pm 228.32$ (range:0-1096/n=25). It was determined that $48 \%$ of $\mathrm{T} 100 \mathrm{cited}$ studies were published in the journals on neuroscience, neurology and brain. It was found that most of the articles were published in the journal of NeuroImage $(n=10)$, and respectively journal of Brain in second place with 7 articles, Nature Reviews NeuroScience, having highest impact factor, in third place with 5 articles and journal of Proceedings of the National Academy of Sciences of the United States of America in fourth place again with 5 articles. In addition, it was observed that IF value and $\mathrm{H}$ index of NeuroImage 
journal, which is in the first rank, was 3.35 and 320 respectively, in the same way, IF value of Nature Reviews NeuroScience journal 21.2 and $\mathrm{H}$ index 375; furthermore, the highest $\mathrm{H}$ index (699) was found of the journal at the fourth rank. It was observed that all of these journals were in "Quartile Score" Q1 category with IF value over 2 (range 2.2-21.2) and H index over 170 (range 171-699) (Table 5). It was determined that the most repeated topics in this trend topic anatomy were neuroscience, radiology nuclear medicine medical imaging, neuroimaging and behavioral science (Table 6).

Table 5: List of journals in which two and more published articles.

\begin{tabular}{|c|c|c|c|}
\hline Journal & Number of articles & IF (2018)* & Q\&H Index(2018)** \\
\hline Neurolmage & 10 & 3.35 & Q1 (320) \\
\hline Brain & 7 & 5.98 & Q1(308) \\
\hline Nature Reviews Neuroscience & 5 & 21.21 & Q1(375) \\
\hline $\begin{array}{l}\text { Proceedings of the National Academy of } \\
\text { Sciences of the United States of America }\end{array}$ & 5 & 5.6 & Q1(699) \\
\hline Brain Research Reviews & 4 & 0 & $-(184)$ \\
\hline Cerebral Cortex & 3 & 3.57 & Q1(223) \\
\hline Journal of Anatomy & 3 & 1.2 & Q1(103) \\
\hline The Journal of Bone and Joint Surgery American Volume (JB\&JS) & 3 & 4.716 & Q1(-) \\
\hline Journal of Comparative Neurology & 3 & 2.2 & Q1(194) \\
\hline Journal of Neuroscience & 3 & 4.1 & Q1(422) \\
\hline Nature & 3 & 16.35 & Q1(1096) \\
\hline American Journal of Sports Medicine & 2 & 3.62 & Q1(196) \\
\hline Anatomical Sciences Education & 2 & 0.96 & Q1(38) \\
\hline Annals of The New York Academy of Sciences & 2 & 1.8 & Q1 (225) \\
\hline Human Brain Mapping & 2 & 2.45 & Q1 (171) \\
\hline Neurology & 2 & 3.5 & Q1(331) \\
\hline Plastic and Reconstructive Surgery & 2 & 1.75 & Q1(160) \\
\hline Trends in Cognitive Sciences & 2 & 7.7 & Q1(276) \\
\hline Trends in Neurosciences & 2 & 6.32 & Q1(269) \\
\hline
\end{tabular}

Note:*IF: Impact Factor (Available from SCR -Scimago 2018), **Q: Quartile Score (Available from SCR -Scimago 2018), **H: H-index (Available from SCR -Scimago 2018)

Table 6: The most common topics among the top 100 cited articles.

\begin{tabular}{|c|c|}
\hline Topic & Number \\
\hline Neurosciences & 56 \\
\hline Radiology Nuclear Medicine Medical Imaging & 14 \\
\hline Neuroimaging & 11 \\
\hline Surgery & 10 \\
\hline Clinical Neurology & 10 \\
\hline Multidisciplinary Sciences & 10 \\
\hline Orthopedics & 5 \\
\hline Anatomy Morphology & 5 \\
\hline Sport Sciences & 4 \\
\hline Behavioral Sciences (Neurobehavioral) & 3 \\
\hline Physiology & 3 \\
\hline
\end{tabular}




\begin{tabular}{|c|c|}
\hline Zoology & 3 \\
\hline Cardiac Cardiovascular Systems & 2 \\
\hline Computer Science Interdisciplinary Applications & 2 \\
\hline Education Scientific Disciplines & 2 \\
\hline Pediatrics & 2 \\
\hline Psychology Developmental & 2 \\
\hline Respiratory System & 2 \\
\hline Urology Nephrology & 2 \\
\hline Computer Science Cybernetics & 1 \\
\hline Critical Care Medicine & 1 \\
\hline Endocrinology Biomedical & 1 \\
\hline Engineering Electrical Electronic & 1 \\
\hline
\end{tabular}

\section{Discussion}

Bibliometric studies provide information about the historical development of the scientific field being studied. Smith Papyrus (1600 BCE), which provides an insight into the status of clinical information in ancient Egypt related to the basic field of anatomy and is regarded as the first recorded rational investigation paper, has maintained its historical position as the first written papyrus [9] to provide information on brain hieroglyphics. In this study, it was found that the most common topics among T100 in the bibliometric analysis of classical articles in the field of anatomy produced between certain years were carried out in the field of brain subjects such as neuroscience (included clinical neurology and neurobehavioral studies), and neuroradiology with nuclear medicine, medical imaging and neuroimaging. Modern brain researches, which were used for the first time in the 1960s and entered into scientific terminology as "neuroscience" and includes many multidiscipline, such as molecular biology, electrophysiology, and computational neuroscience, began to be mentioned in the literature with this term. Thus, many neural connections in the human brain have been revealed. Neuroscience, including anatomybased various studies, has gained momentum in the last four decad by including neuroradiology/neuroimaging studies and has been the pioneer of many basic and clinical researches. Specifically, the use of radiological techniques to show cross-sectional and threedimensional anatomical structures has increased the relationship between anatomy and clinical practice and social area [10]. Having stated that the relationship between anatomy and radiology disciplines continues to grow in an interactive relationship, [11] foretold that signals of the transition from general anatomy to functional anatomy were given. Continuous technical progress is changing the capability of medical imaging techniques almost every day, currently allowing for more and more accurate and comprehensive anatomical studies of living human beings $[12,13]$. Galen was modest about the potential of anatomy for understanding brain function and said that: "How the brain performs its functions in imagination, in reasoning, in thinking and in memory. I can form no opinion whatsoever. Nor do I think that anything more will be found out by anatomy" [14].

On the other hand, Jones (2002) emphasized that numerous questions in the clinical neurosciences can be tackled by anatomical research. However, we see that anatomy is still important understanding brain functions (as well as depicting the human brain in activity with functional MRI). In fact, these developments contribute to our access to the best knowledge on anatomy. It was found that three of among the most cited 100 publications were classified in the field of zoology. The reason for this was that the comparative anatomy studies encouraged references to brain functions among species known as system neuroscience, which could be considered about zoology. In this study, most of the studies in the field of neuroscience were experimental and review studies. It was observed that review studies received more citations in the main study areas. The reason is that review studies have been prepared with comprehensive and holistic approach to review studies. As expected, the USA is ranked as the country with the highest number of publications, in terms of the number of publications per institute, while it was seen that the authors working in the organizations of UK contributed the most. Although the axis of the study topics focuses in the direction of neuroscience, morphological anatomy still constitutes the basis of the studies. Jones et al. [15] argued that the shift to these changes was in fact caused by a less prestigious perception of general anatomical research. Nevertheless, in the main subject ranking of this T100 study, after neuroscience topics, the presence of many studies on subjects such as general, structural, clinical, sports, surgery and systematic anatomy, has shown that general anatomy studies are still important in maintaining. Meanwhile, in this anatomicbased classical article, the use of technological innovations, such as computer science-based interdisciplinary applications and cybernetics, which had never been encountered before, was outstriking in anatomical research. The reason for this is thought that biomedical investigations, especially diffusion-tensor MRI, which support functional imaging may be adaptation studies to anatomic 
atlases. In addition, a new field such as Computational Anatomy, which shows a translational tendency to neuroradiologic imaging devices, can be suggested.

In this study, the number of articles published by years showed consistent with the Poisson distribution between the years of 1993 and 2013. Poisson distribution of articles by years can be explained as follows: Increasing communication network with developing technology, facilitating access to current literature (Pubmed, Science direct, Web of science, Index Medicus and etc.), and evolution of studies in functional direction by rapid advancement of imaging technology can explain the increase in the number of studies in these years. Multiple bibliometric indices can be used to evaluate different aspects of the study. At the present time, although the number of citations of the article and the impact factor (IF), $\mathrm{Q}$ category and $\mathrm{H}$ index of the journal are very important in the evaluation of the quality of an article, having the highest impact factor and $\mathrm{H}$ index is not an indication of the preferableness of that journal in that area in terms of the number of articles. IF is a measure of how often an article in a journal is shown on average in a given year. It is used to measure the importance or ranking of the journal by calculating the citations of the articles. The calculation is based on a two-year period and involves dividing the number of articles by the number of cited articles [16]. Citation is an important indicator reflecting the interest shown by other authors to an article and the quality of the article in general. It is generally accepted that the number of citations is related to the quality or usefulness of the research [17]. Year of publication and number of citations for an article is closely related and the number of citations grows as the time passes.

It is well known that bibliometric studies based on citation rates have some limitations. Although each citation shows that a scientific idea encourages another research in its own work, selfcitation results in artificial inflation. In addition, there may be a high number of citations in research areas that are politically controversial or of current interest. However, there is a positive correlation between the high number of citations and the time after publication. This, on the other hand, reflects the time bias in evaluating the quality of the article. Therefore, to balance time bias in bibliometric studies, the ACI assessment should also be included. $\mathrm{ACI}$ can be considered as the average number of citations received each year since the publication of the manuscript. Looking at the most cited articles, it was observed that most of these articles were related to neuroscience and the order of cite and ACI indexes were not compatible with the time cited order. For example, the ACI index of the fifth article should actually be third. Therefore, in this topic trend study, ACI values were also calculated to remove time-based bias. It was thought that thus, a more objective article evaluation was provided. The number of citations may be high in research areas that are politically controversial or of current interest. In contrast, low citations will be made in journals that feed small research areas. This can be explained, on the other hand, by the choice of the publication of a specific article which determines the preferableness of the journal, or the fact that it accepts a limited number of articles.

This can also be called author-based bias. In our study, it was observed that the factor affecting the gradient of the highest-cited article and the lowest-cited article is mainly related to neuroscience studies and the lowest cite articles were found to be more of a corner stone. The reason for the lack of structural anatomy research can be considered as the fact that the inclusion of functional and anatomy studies in clinical field studies has narrowed the working area of anatomy specialists. The fact that anatomy studies were included in neuroscience and neuroimaging studies showed the ongoing dynamic process of the examinations in terms of neuroanatomical research. Anatomy studies, which are trapped in radiological and clinical studies, may be a parameter that maintains the current value of gross, physiological and pathological anatomy. Except for the bibliometric study on insula and the anatomical research using neuroimaging techniques as a local anatomical structure illustrating the intersections of other areas with anatomy, no other anatomy bibliometric study was found in the literature. On the basis of all basic and clinical research, there is the fact to know all aspects of the human body and to determine the most beneficial intervention without harming human beings before the transition to clinical applications. Therefore, although disciplines change, it is thought that anatomical structure researches will maintain the necessity and importance of all medical information.

\section{Limitations}

In addition to time citation resistant limitations specific to bibliometric studies, limitations specific to anatomy were also determined. In this context, many neurophysiology studies encountered with the basic field of physiology have caused some limitations in anatomical classification. When the studies which are used specifically in physiology studies and include the terms in the exclusion criteria are examined carefully, these were evaluated as function studies on neuroanatomic structures. Although the study named "The brain's default network: anatomy, function, and relevance to disease" which is in the first rank among Top 100 articles includes the term "default", it was included in the study because it included more of the emphasis on the "default system anatomy". It was understood that the study was in fact a neuroanatomy-based neuroscience study. This update study provides new insights into the dynamic nature of anatomy research. The methods used were completely quantitative and therefore, these methods were objective, reliable and easily reproducible; this, on the other hand, allowed the identification of subtle trends.

\section{Conclusion}

Although it has some bias, bibliometric studies give us valuable information in the field of anatomy. Although anatomicbased research has gradually evolved towards neuroanatomy and neuroscience, anatomical morphology studies remain 
important. However, new technology-based studies have shown that more research is needed in neuroscience and neuroimaging studies that do not identify the forces affecting the direction of neuroanatomical researches. The use of computer science-based technologies has attracted attention to in the realm of anatomy. It is clearly understood that anatomy studies are still seen as the main application area of all medical information.

\section{Conflict of Interest}

The author declares that there is no conflict of interest.

\section{References}

1. Anson B J (1945) The Initial Letters of 1555 Edition of Vesalius's Fabrica. Q Bull Northwest Univ Med Sch 19(4): 326-335.

2. Eggertson L (2010) Lancet retracts 12-year-old article linking autism to MMR vaccines. CMAJ 182(4): E199-E200.

3. Garfield E (1987) 100 citation classics from the Journal of the American Medical Association. JAMA 257: 52-9.

4. Garfield E (1999) Journal impact factor: A brief review. CMAJ 161(8): 979-980.

5. Grignon B (2012) Anatomy and medical imaging: A symbiotic relationship. Surg Radiol Anat 34(8): 673-674.

6. Gross CG (2009) History of Neuroscience: Early Neuroscience. Encyclopedia of Neuroscience Academic Press: 1167-1171.

7. Jones DG, Dias GJ, Mercer S, Zhang M, Nicholson HD (2002) Clinical anatomy research in a research-driven anatomy department. Clin Anat 15(3): 228-232.

ISSN: 2574-1241

DOI: 10.26717/BJSTR.2019.22.003717

Emine Petekkaya. Biomed J Sci \& Tech Res

(C) (i) This work is licensed under Creative

Commons Attribution 4.0 License

Submission Link: https://biomedres.us/submit-manuscript.php
8. Joyce CW, Joyce KM, Sugrue CM, Kelly JC, Carroll SM, et al. (2014) Plastic Surgery and the Breast: A Citation Analysis of the Literature. Plast Reconstr Surg Glob Open 2(11): e251.

9. Li Q, Jiang Y (2016) Top classic citations in pancreatic cancer research. World J Surg Oncol 14: 298.

10. Siddiquey AKS, Husain SMS, Laila SZH (2009) History of Anatomy Bangladesh J Anat 7(1): 1-3.

11. (2011) SIGN 50 Scottish Intercollegiate Guidelines Network; SIGN 50 (in: A Guideline developer's handbook Re, November 2011), Healthcare Improvement Scotland. Healthcare Improvement Scotland.

12. Standring S (2016) A brief history of topographical anatomy. J Anat 229(1): 32-62.

13. Tubbs RI, Gonzales J, Iwanaga J, Loukas M, Oskouian RJ, et al. (2018) The influence of ancient Greek thought on fifteenth century anatomy: Galenic influence and Leonardo da Vinci. Childs Nerv Syst 34(6): 10951101.

14. Van Raan AFJ (2003) The use of bibliometric analysis in research performance assessment and monitoring of interdisciplinary scientific developments. Technology assessment Theory and practice 12: 20-29.

15. Wilcox MA, Khan NR, McAbee JH, Boop FA, Klimo P Jr (2013) Highly cited publications in pediatric neurosurgery. Childs Nerv Syst 29(12): 2201-2213.

16. Wing L, TF Massoud (2015) Trends in Performance Indicators of Neuroimaging Anatomy Research Publications: A Bibliometric Study of Major Neuroradiology Journal Output Over Four Decades Based on Web of Science Database. Clinical Anatomy 28(1): 16-26.

17. Yeung AWK (2018) The 100 Most Cited Papers Concerning the Insular Cortex of the Brain: A Bibliometric Analysis. Frontiers in Human Neuroscience 12: (337).

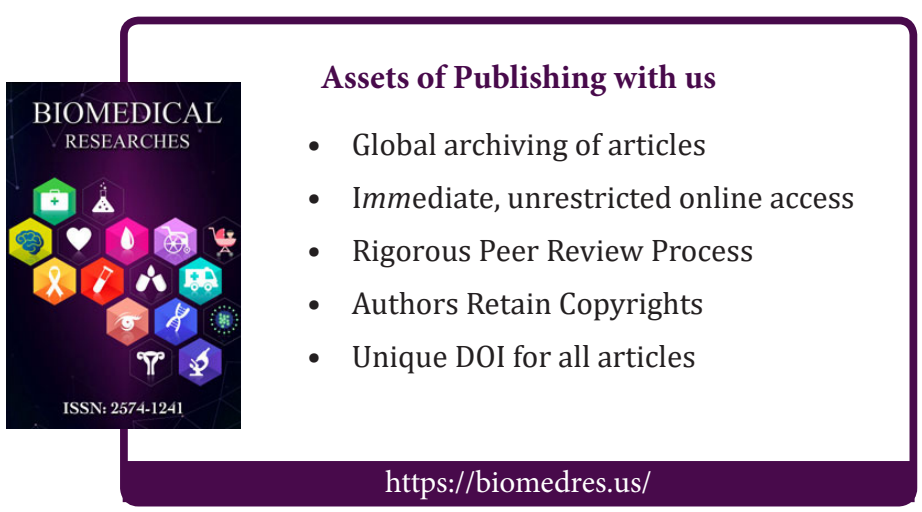

